\title{
Aplikasi Monitoring Traffic And Notification Peradilan Pada Pengadilan Agama Serang Menggunakan Teknologi Web
}

\section{Service}

\author{
${ }^{1}$ Reza Darmawan, ${ }^{2}$ Haris Triono Sigit, ${ }^{3}$ Ahmad Sugiyarta \\ 1,2,3 Jurusan Informatika, Fakultas Teknologi Informasi, Universitas Serang Raya \\ Jl. Raya Serang - Cilegon Km. 05 (Taman Drangong), Serang - Banten \\ E-mail: rezadarmawan444@gmail.com ${ }^{1)}$,haris.t.sigit@gmail.com ${ }^{2}$, ahmad.sugiyarta@yahoo.com ${ }^{3)}$
}

\begin{abstract}
Abstrak - Pengadilan agama adalah pengadilan tingkat pertama yang melaksanakan kekuasaaan kehakiman dilingkungan peradilan agama yang berkedudukan di ibu kota kabupaten atau kota. Pengadilan agama menyelenggarakan penegakan hukum dan keadilan di tingkat pertama bagi rakyat pencari keadilan perkara tertentu antara orang yang beragama islam di bidang perkawinan, waris, wasiat, hibah, wakaf, zakat, infaq, shadaqah dan ekonomi syari'ah. Susunan pengadilan agama terdiri dari ketua pengadilan, hakim anggota, panitera, sekretaris, jurusita. Selama ini pihak berperkara sangat kesulitan untuk melakukan pemantauan berkala tidak hanya itu pemberkasan perkara pun terasa lamban karena harus diketik manual oleh panitera menggunakan aplikasi Microsoft Office Word. Oleh karena itu, aplikasi ini dibuat agar memudahkan pihak berperkara untuk memantau terhadap perkaranya begitupun dengan pihak internal Pengadilan Agama Serang mulai dari hakim, panitera, jurusita dan ketua Pengadilan Agama Serang harus cek data satu persatu secara berkala. Aplikasi ini dibangun dengan menggunakan bahasa pemrograman PHP, JAVA, dan MySQL sebagai basis data dan dengan menggunakan metode Extreme Programming, sebuah pendekatan atau model pengembangan perangkat lunak yang mencoba menyederhanakan berbagai tahapan dalam proses pengembangan aplikasi ini sehingga menjadi lebih adaptif dan fleksibel. dengan metode ini bukan hanya berfokus pada pengkodean tapi meliputi seluruh area pengembangan perangkat lunak, karena Extreme Programming mengambil pendekatan 'ekstrim' dalam iterative development. Penelitian dilakukan pada Pengadilan Agama Serang dan pengumpulan data tentang keperluan data apa saja yang dibutuhkan oleh pengguna aplikasi ini. Pada saat testing aplikasi menggunakan black box. Maka menghasilkan aplikasi berbasis website dan mobile yang mampu membantu memberikan informasi seputar perkara dan memberikan kemudahan untuk mencetak berkas persidangan pada Pengadilan Agama Serang.
\end{abstract}

Kata Kunci: Black Box, Extreme Programming, Monitoring, Notification, Traffic, Web Service

\section{PENDAHULUAN}

Latar Belakang

Pengadilan agama adalah pengadilan tingkat pertama yang melaksanakan kekuasaaan kehakiman dilingkungan peradilan agama yang berkedudukan di ibu kota kabupaten atau kota. Pengadilan agama di bentuk dengan keputusan presiden. Pembentukan tersebut berdasarkan UU No.18 tahun 2001 dan Kepres No.11 tahun 2003 tentang Mahkamah Syar'iyah dan Mahkamah Syar'iyah Provinsi. Pengadilan agama menyelenggarakan penegakan hukum dan keadilan di tingkat pertama bagi rakyat pencari keadilan perkara tertentu antara orang yang beragama islam di bidang perkawinan, waris, wasiat, hibah, wakaf, zakat, infaq, shadaqah dan ekonomi syari'ah. Susunan pengadilan agama terdiri dari ketua pengadilan, hakim anggota, panitera, sekretaris, jurusita.
Pada kegiatan peradilan banyak sekali menemukan perkara yang bermasalah antara lain jadwal sidang belum diinput atau perkara sudah selesai tapi statusnya belum dirubah dan pihak perkara kesulitan untuk mengetahui status perkaranya dikarenakan tidak adanya alat atau sistem untuk memantau proses peradilan. Maka dari itu untuk membuat proses peradilan yang baik dan modern pengadilan agama Serang menunjuk petugas informasi untuk memonitoring proses peradilan dan melakukan pemberitahuan terhadap pihak yang terkait dengan perkara tersebut 2

Tujuan dilakukannya penelitian ini adalah untuk merancang aplikasi monitoring traffic and notification peradilan di pengadilan agama Serang guna untuk mempermudah petugas informasi dan pihak yang berperkara dipengadilan agama serang dalam memantau perkara bermasalah, memantau alur peradilan dan 
memberikan notification /pemberitahuan terhadap pihak yang perkaranya bermasalah.

\section{Rumusan Masalah}

Berdasarkan fakta diatas maka dapat dirumuskan permasalahan dalam penelitian ini adalah bagaimana membangun aplikasi untuk memantau proses peradilan dan menampilkan pemberitahuan atau notifikasi terhadap majelis hakim dan pihak yang sedang menjalani proses peradilan?

\section{Tujuan Penelitian}

Adapun tujuan penelitian ini adalah :

"Membangun aplikasi untuk memantau proses peradilan dan menampilkan pemberitahuan atau notifikasi terhadap majelis hakim maupun pihak yang sedang melakukan proses peradilan di pengadilan agama Serang."

\section{LANDASAN TEORI}

\section{Monitoring Traffic and Notification}

Monitoring menurut Calyton dan Petry 1983 adalah sebagai proses mengukur, mencatat, memantau dan mengkomunikasikan informasi untuk membantu pengambilan keputusan.

Traffic menurut Beckham traffic artinya lalu lintas atau alur dari proses yang di jalankan.

Notification atau dalam bahasa indonesianya notifikasi menurut kamus besar bahasa indonesia (KBBI) adalah pemberitahuan atau kabar tentang informasi yang terkait.

Jadi bisa di katakan Monitoring Traffic and Notification adalah aktifitas yang ditujukan untuk memberikan informasi tentang suatu alur data dan memberikan informasi perihal suatu alur data tersebut.

\section{Website}

Website adalah suatu kumpulan-kumpulan halaman yang menampilkan berbagai macam informasi teks, data, gambar diam ataupun bergerak, data animasi, suara, video maupun gabungan dari semuanya. Baik itu berupa statis maupun dinamis, yang dimana membentuk suatu rangkaian bangunan yang saling berkaitan dimana masing masing dihubungkan dengan jaringan halaman atau hyperlink.

\section{Android}

Android adalah sebuah sistem berbasis java yang berjalan pada Kernel Linux 2.6. Android dirilis oleh Google, dibawah Open Heandset Alliace, pada November 2007. Bersamaan dengan peluncuran tersebut, Google membuat pusat Development Tool dan panduan untuk menjadi pengambang pada sistem tersebut. File panduan Software Development Kit (SDK), dan komunitas pengembang dapat diperoleh pada website resmi
Google Android. Android menawarkan sebuah lingkungan yang berbeda untuk pengembang. Setiap aplikasi memiliki tingkatan yang sama. Android tidak membedakan antara aplikasi inti dengan aplikasi pihak ketiga. Application Programming Interface (API) yang disediakan menawarkan akses ke hardware, maupun data - data ponsel sekalipun, atau data sistem sendiri. Bahkan pengguna dapat menghapus aplikasi inti dan menggantikannya dengan aplikasi pihak ketiga

Kini android sudah mencapai versi 7 yaitu android oreo.

\section{MySQL}

MySQL adalah sistem manajeman database SQL yang bersifat Open Source dan paling popular saat ini. Sistem Database MySql mendukung beberapa fitur seperti multithreaded, multi user, dan SQL database manajemen sistem (DBMS). Database ini di buat untuk keperluan sistem Database yang cepat, handal dan mudah digunakan.

\section{PHP}

Menurut Sibero (2012:49),'PHP (Personal Home Page) adalah program (interpreter) adalah proses penerjemah baris sumber menjadi kode mesin yang dimengerti komputer secara langsung pada saat baris kode di jalankan".

Menurut Kustiyahnigsih (2011:114), "PHP (atau resminya PHP: Hypertext Procesor) adalah skrip bersifat bersifat server side yang di kembangkan kedalam HTML. PHP sendiri merupakan singkatan dari Personal Home Page Tools. Skrip ini akan membuat suatu aplikasi dapat di intergrasikan ke dalam HTML sehingga suatu halaman web tidak bersifat statsi, namum bersifat dinamis. Sifat server side berarti pengerjaan kode program dilakukan di server, baru kemudian hasilnya dikirimkan ke browser".

Berdasarkan pengertian di atas, dapat ditarik kesimpulan bahwa PHP (PHP: Hypertext processor) adalah suatu bahasa pemograman yang digunakan untuk menerjemahkan baris kode program menjadi kode mesin yang dapat dimengerti oleh komputer yang bersifat server-side yang dapat di kembangkan ke dalam HTML. Perkembangan bahasa pemrograman PHP dirasa cukup cepat dan sudah menginjak versi ke 7 .

\section{FCM}

Firebase pertama kali didirikan pada tahun 201 oleh Adrew Lee dan James Tamplin. Produk yang pertama kali di kembangkan adalah Realtime Database, dimana developer dapat menyimpan dan melakukan sinkronisasi data kebanyak user. Kemudian berkembang menjadi layanan penyedia pengembangan aplikasi pada oktober 2014, 
perusahaan tersebut diakuisisi oleh Google.

Berbagai fitur terus di kembangkan hingga diperkenalkan fitur baru bernama Firebase Cloud Messaging (FCM).

Firebase Cloud Messaging (FCM) adalah solusi pengiriman pesan lintas platform yang andal dan memungkinkan Anda mengirim pesan tanpa biaya. Dengan FCM, Anda dapat memberi tahu/notifikasi ke aplikasi klien bahwa data baru atau yang lainnya tersedia untuk disinkronkan.

\section{Undified Modeling Language (UML)}

Menurut Nugroho (2010:6), "UML (Unified Modeling Language) adalah 'bahasa' pemodelan untuk sistem atau perangkat lunak yang berparadigma 'berorientasi objek". Pemodelan (modeling) sesungguhnya digunakan untuk penyederhanaan permasalahan-permasalahan yang kompleks sedemikian rupa sehingga lebih mudah dipelajari dan dipahami”.

Menurut Nugroho (2009:4), "UML (Unified Modeling Language) adalah Metodologi kolaborasi antara metoda-metoda Booch, OMT (Object Modeling Technique), serta OOSE (object Oriented Software Enggineering) dan beberapa metoda lainnya, merupakan metodologi yang paling sering digunakan saat ini untuk analisa dan perancangan sistem dengan metodologi berorientasi objek mengadaptasi maraknya penggunaan bahasa "pemrograman berorientasi objek" (OOP)".

Berdasarkan pendapat yang dikemukakan di atas dapat ditarik kesimpulan bahwa "Unified Modelling Language (UML) adalah sebuah bahasa yang berdasarkan grafik atau gambar untuk menvisualisasikan, menspesifikasikan, membangun dan pendokumentasian dari sebuah sistem pengembangan perangkat lunak berbasis Objek (Object Oriented programming).

\section{Extreme Programming (XP)}

Extreme Programming (XP) merupakan salah satu metodologi rekayasa perangkat lunak yang banyak di gunakan untuk mengembangkan aplikasi oleh para developer. XP diperkenalkan oleh Kent Beck ketika ia di tunjuk untuk menangani sebuah proyek penggajian dari chrysler yang di kenal dengan C3 (Chrysler Comprehensive Compensation).

Proyek ini di mulai karena rumitnya sistem yang di buat dan kegagalan pada saat memasuki tahap uji sistem (testing). Pihak Chrysler akhirnnya menyewa Kent Beck sebagai konsultan di bidang software engineering. Kemudian ia di kenal sebagai pencetus XP.

XP sangat cocok untuk pengembangan proyek yang memerlukan adaptasi cepat dalam perubahanperubahan yang terjadi selama pengembangan aplikasi. XP juga cocok untuk anggota tim yang tidak teralu banyak dan berada pada lokasi yang sama dalam pengembangan sistem.

\section{Metodologi Penelitian}

Dalam penelitian ini metode yang digunakan adalah Extreme Programming, dimana XP ini memiliki 4 (enam) tahapan yaitu planning, design, coding dan, testing.

a. Planning

Adapun kegiatan yang dilakukan pada tahap planning adalah sebagai berikut:

1. Memahami Konteks Bisnis

2. Mendefinisikan Output

3. Fitur Pada Aplikasi

4. Fungsi Dari Aplikasi

5. Penentuan Waktu

6. Alur Pengembangan Aplikasi

b. Design

Metodologi XP menekankan pada desain sistem yang sederhana, lebih fokus pada pembuatan program dan uji program. Hal ini dikarenakan XP memanfaatkan waktu pendek, sehingga dengan kartu CRC (Class Responsibillity Collaborator) sudah cukup untuk mewakili desain sistem.

c. Coding

Pada tahap coding kegiatan yang dilakukan yaitu :

Dokumentasi pembuat basis data, dan dokumentasi pembuatan program.

1. Membuat Basis Data

2. Membuat Program

d. Testing

Berbeda dengan model waterfall, pada model waterfall pengujian (testing) dilakukan apabila semua program sudah selesai dibuat baru dilanjutkan tahap uji aplikasi. Pada model XP testing dapat dilakukan kapan saja, tidak perlu menunggu seluruh aplikasi selesai dibuat. Dapat dilakukan uji per modul, bila ada kesalahan dapat terdeteksi dari awal. Sehingga programmer dapat mengetahui kesalahan dari awal dan cara penanganannya. Komunikasi antara pengembang (developer) dengan pengguna sangat diperlukan dalam metodologi XP .Pada tahap testing ini menggunakan metode testing dengan blackbox.

\section{HASIL DAN PEMBAHASAN}

Berikut sedikit dari beberapa hasil dari produksi yang telah dibuat: 


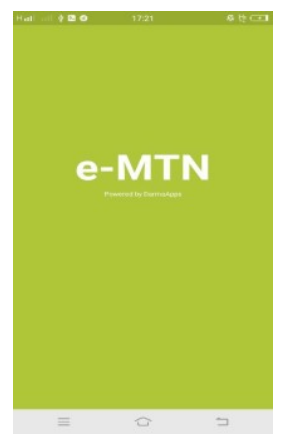

Gambar 1. Menampilkan halaman splash screen

a. Pada halaman ini menampilkan onboard screen

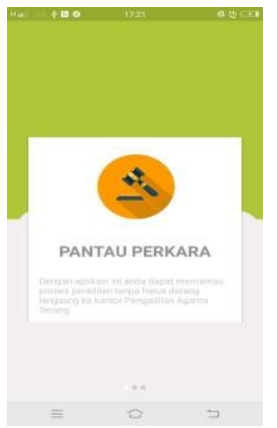

\section{Gambar 2. Menampilkan Tampilan onboard} screen

b. Halaman Scan KPE (Kartu Perkara Elektronik)

Halaman scan KPE adalah halaman yang memuat pembacaan kartu perkara elektronik untuk masuk ke halaman utama aplikasi.

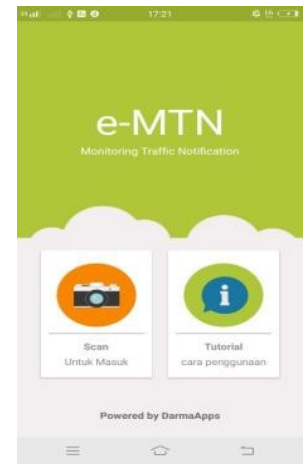

\section{Gambar 3. Menampilkan Tampilan Scan} KPE

c. Halaman Utama Pihak

Halaman utama pihak adalah halaman yang memuat menu-menu aplikasi dan diperuntukan hanya untuk pihak yang sedang berperkara

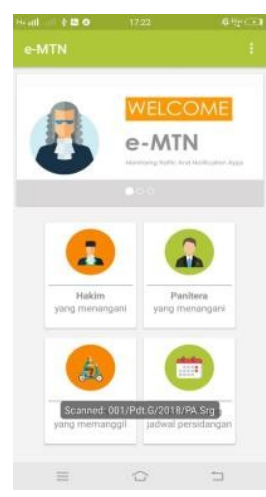

\section{Gambar 4. Menampilkan Tampilan Utama Pihak}

d. Halaman Penetapan Hakim

Halaman penetapan hakim adalah halaman yang memuat informasi hakim yang menangani perkara.

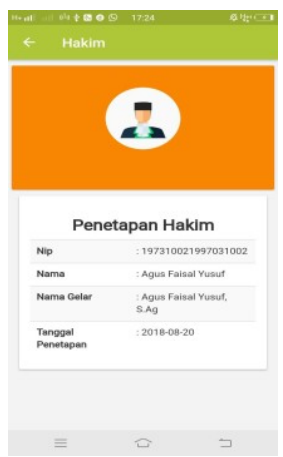

\section{Gambar 5. Menampilkan Tampilan Penetapan Hakim}

e. Halaman Penetapan Panitera

Halaman penetapan panitera adalah halaman yang memuat informasi panitera yang menangani perkara.
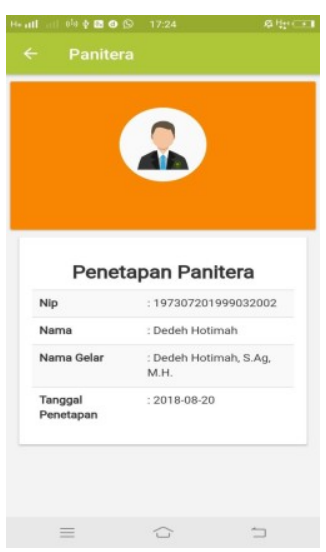

\section{Gambar 6 . Menampilkan Tampilan} Penetapan Panitera

f. Halaman Penetapan Jurusita

Halaman penetapan jurusita adalah halaman yang memuat data seputar jurusita yang bertugas mengantarkan surat panggilan sidang kepada pihak yang berperkara. 


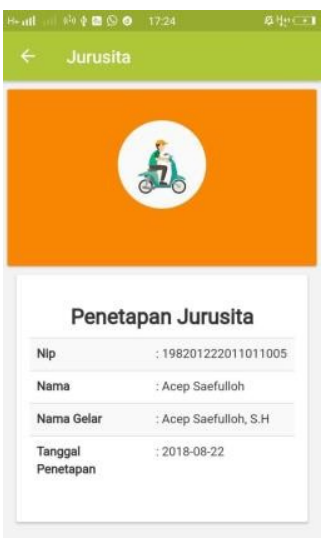

\section{Gambar 7. Menampilkan Tampilan Penetapan Jurusita}

\subsection{Pengujian}

Pengujian sistem yang dilakukan untuk uji fungsi dari aplikasi monitoring traffic and notification peradilan yaitu menggunakan blackbox, balckbox itu sendiri adalah pengujian sistem hanya dari luarnya saja atau fungsi fungsinya saja sudah berjalan dengan baik atau belum. Berikut ini adalah gambaran blackbox untuk pengujian sistem :

\begin{tabular}{|c|c|c|c|}
\hline No & Skenario Pengujian & Hasi Yang Diharapkan & Kesimpulan \\
\hline 1 & $\begin{array}{l}\text { Mengisi Username, } \\
\text { password yang sudah } \\
\text { terdaftar disistem dan } \\
\text { klik tombol login }\end{array}$ & $\begin{array}{l}\text { Muncul notifikasi login } \\
\text { berhasil dan menampilkan } \\
\text { halaman utama }\end{array}$ & OK \\
\hline 2 & $\begin{array}{l}\text { Klik menu penetapan } \\
\text { dan pilih perkara yang } \\
\text { akan ditetapkan petugas } \\
\text { peradilannya } \\
\end{array}$ & $\begin{array}{l}\text { Muncul halaman detail perkara } \\
\text { dan form penetapan petugas } \\
\text { peradilan }\end{array}$ & OK \\
\hline 3 & $\begin{array}{l}\text { Klik tetapkan hakim } \\
\text { pilih hakim yang akan } \\
\text { memimpin sidang dan } \\
\text { klik simpan }\end{array}$ & $\begin{array}{l}\text { Muncul notifikasi hakim } \\
\text { berhasil ditetapkan, dan data } \\
\text { penetapan tersimpan ke } \\
\text { database }\end{array}$ & $\mathrm{OK}$ \\
\hline 4 & $\begin{array}{l}\text { Klik tetapkan panitera } \\
\text { dan pilih panitera }\end{array}$ & $\begin{array}{l}\text { Muncul notifikasi panitera } \\
\text { berhasil ditetapkan, dan data } \\
\text { penetapan tersimpan ke } \\
\text { database }\end{array}$ & OK \\
\hline 5 & $\begin{array}{l}\text { Klik tetapkan jurusita } \\
\text { dan pilih jurusita }\end{array}$ & $\begin{array}{l}\text { Muncul notifikasi jurusita } \\
\text { berhasil ditetapkan, dan data } \\
\text { penetapan tersimpan ke } \\
\text { database }\end{array}$ & OK \\
\hline 6 & $\begin{array}{l}\text { Klik tetapkan jadwal } \\
\text { sidang isi form yang ada }\end{array}$ & $\begin{array}{l}\text { Muncul notifikasi jadwal } \\
\text { sidang berhasil ditetapkan, dan } \\
\text { data penetapan tersimpan ke } \\
\text { database }\end{array}$ & OK \\
\hline 7 & \begin{tabular}{|l|} 
Klik new KPE dan isi \\
nomor perkara yang \\
baru terdaftar di \\
pengadilan agama \\
serang klik generate \\
\end{tabular} & $\begin{array}{l}\text { Menampilkan qrcode hasil } \\
\text { generate dari nomor perkara }\end{array}$ & OK \\
\hline 8 & Klik menu monitoring & $\begin{array}{l}\text { Menampilkan data-data hakim } \\
\text { beserta perkara yang ditangani } \\
\text { dan juga masalah masalah } \\
\text { yang ada. }\end{array}$ & $\mathrm{OK}$ \\
\hline 9 & $\begin{array}{l}\text { Klik tombol scan dan } \\
\text { dekatkan KPE ke } \\
\text { kamera smartphone }\end{array}$ & $\begin{array}{l}\text { Menampilkan data data } \\
\text { perkara pribadi pihalk beserta } \\
\text { status terakhir perkara pihak }\end{array}$ & $\mathrm{OK}$ \\
\hline 10 & $\begin{array}{l}\text { Pilih range tanggal dan } \\
\text { klik cetak laporan } \\
\text { minutasi }\end{array}$ & $\begin{array}{l}\text { Menampilkan hasil cetakan } \\
\text { laporan minutasi berupa file } \\
\text { pdf }\end{array}$ & $\mathrm{OK}$ \\
\hline
\end{tabular}

\section{SIMPULAN}

Berdasarkan pembahasan pada analisis, desain, implementasi dan pengujian yang telah dilakukan, maka dapat ditarik kesimpulan yaitu :
Aplikasi ini dibangun dengan menggunakan metode extreme programming agar pengerjaan lebih fleksibel dan cepat. Untuk bahasa pemogramannya menggunakan PHP dan JAVA, bahasa pemgoraman PHP untuk aplikasi berbasis web yang digunakan oleh pihak internal Pengadian Agama Serang, sedangkan bahasa pemograman JAVA untuk aplikasi berbasis android yang digunakan oleh pihak berperkara. Media penyimpanan atau basis data yang digunakan adalah MYSQL dan untuk notifikasi menggunakan jasa ketiga yaitu Firebase Cloud Message agar notifikasi berjalan secara realtime. Aplikasi ini telah di bangun dengan baik sehingga dapat mempermudah pihak berperkara, hakim, jurusita, panitera dan ketua Pengadilan Agama Serang untuk melakukan pemantauan alur peradilan yang ada di Pengadilan Agama Serang.

\section{PUSTAKA}

Abdul Latif Afandi, (2014) Melakukan Penelitian Tentang "Sistem informasi manajemen berkas (E-BERKAS) studi kasus: Pelanggan PT.TELKOM Surabaya Selatan. Universitas Narotama Surabaya".

Alexander F.K. Siberp. 2014. Web Programming POWER PACK. Yoyakarta : MediaKom

Ferry, Elis, Fera (2017) Melakukan Penelitian Tentang "aplikasi monitoring proses pembuatan pakaian berbasis web". Universitas Telkom, Bandung.

Mita Rohayati (2014) Melakukan Penelitian Tentang "Membangun Sistem Informasi Monitoring Data Inventori Di Vio Hotel Indonesia”. Universitas Komputer Indonesia, Bandung.

M. R. Arief, Pemograman Web Dinamis Menggunakan PHP \& MySQL, Yogyakarta: Andi, 2011

Muhammad, Nur, Sari, Toufan (2017) Melakukan Penelitian Tentang "Aplikasi Monitoring Laporan Stok Barang Wormhole Makasar Berbasis Web". Universitas Telkom, Bandung.

Nurhasanah, Sari, Toufan (2017) Melakukan Penelitian Tentang "Aplikasi Monitoring Peserta Kerja Praktek Berbasis Web Di Pt Industri Telekomunikasi Indonesia (PERSERO)". Universitas Telkom, Bandung.

Utariani, Herkules (2017) Melakukan Penelitian Tentang "Monitoring Bimbingan Skripsi Online Pada Sekolah Tinggi Manajemen Informatika Dan Komputer (STMIK) Palangka Raya ". STMIK Palangka Raya, Palangka Raya. 